\title{
Perfil dos discentes de Odontologia da Universidade Estadual do Piauí
}

\author{
Beatriz da Silva Rocha*; Samuel Fontes Batista**; Maria Ângela Arêa Leão Ferraz***
}

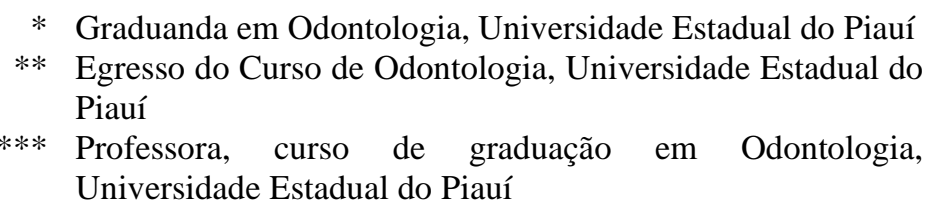
Recebido em 21/06/2018. Aprovado em 22/12/2019.

\begin{abstract}
RESUMO
O presente estudo teve como objetivo conhecer o perfil acadêmico e sociodemográfico dos estudantes de Odontologia da Universidade Estadual do Piauí. A pesquisa foi do tipo transversal com abordagem quantitativa. Aplicou-se um questionário contendo perguntas a respeito dos aspectos socioeconômicos e acadêmicos dos discentes. Dos 92 estudantes matriculados, $71 \%$ (66) participaram do estudo, desses 59\% (39) são mulheres, 92\% (61) solteiros(as), 59\% (39) com idade entre 21 e 24 anos, $38 \%$ (25) de classe econômica favorecida e $44 \%$ (29) que se autodeclaram brancos. Quanto ao motivo de escolha do curso, desejo pessoal foi a resposta escolhida por 48,50\% (32) dos discentes. A pesquisa científica foi classificada como muito importante durante a formação e após a graduação, $97 \%$ (64) pretendem fazer especialização, sendo Cirurgia $(16,24 \%)$ e Ortodontia $(13,20 \%)$ as áreas de maior interesse. As perspectivas quanto à profissão se relacionam com a realização pessoal/profissional e promoção de saúde. Com base nos resultados, identificou-se o perfil do estudante de Odontologia da Universidade Estadual do Piauí, suas expectativas e o que pretendem realizar após a formação.
\end{abstract}

Descritores: Odontologia. Estudantes. Mercado de Trabalho.

\section{INTRODUÇÃO}

A avaliação do ensino público e privado pelo Ministério da Educação tem instigado debates e revisões nas diferentes áreas de atividade, estimulando as universidades a conhecerem melhor seus estudantes, como forma de aprimorar a qualidade de ensino e entregar ao mercado de trabalho profissionais capacitados ${ }^{1}$.
Em fevereiro de 2002, quando as Diretrizes Curriculares Nacionais (DCN) dos cursos de graduação em Odontologia foram estabelecidas, traçaram um perfil generalista do profissional a ser formado no Brasil e enunciaram habilidades e competências que deveriam ser desenvolvidas pelo cirurgião-dentista, novos caminhos foram buscados para responder ao desafio proposto e isso incluiu a 
reformulação de projetos pedagógicos e matrizes curriculares. Desde então, pesquisas foram realizadas buscando entender o perfil do estudante de Odontologia formado nas instituições de ensino superior do Brasil frente a essas mudanças ${ }^{2}$.

De acordo com o Instituto Nacional de Estudos e Pesquisas Educacionais (INEP/MEC), o número de vagas dos cursos de graduação em Odontologia, segundo as regiões do Brasil, aumentou de forma considerável nas regiões Norte e Nordeste ${ }^{3}$. A Universidade Estadual do Piauí (UESPI) implantou o curso de bacharelado em Odontologia em 2005 e desde 2012 a seleção é realizada através do Sistema de Seleção Unificada (SISU), com reservas de vagas para egressos de escolas públicas e negros, promovendo maior diversidade quanto ao perfil dos estudantes.

Conhecer o perfil do estudante de graduação fornece à instituição dados para adequar a matriz curricular às suas necessidades. Nesse sentido, houve interesse em conhecer o perfil acadêmico e sóciodemográfico dos estudantes do curso de Odontologia da Universidade Estadual do Piauí/UESPI, campus Professor Alexandre Alves de Oliveira, Parnaíba/PI, buscando conhecer também, suas expectativas e dificuldades esperadas quanto à futura profissão.

\section{METODOLOGIA}

O estudo foi aprovado pelo Comitê de Ética em Pesquisa da UESPI com parecer número 1.775.484. Obteve-se, junto à coordenação do curso de Odontologia, a lista de discentes devidamente matriculados, totalizando 92 estudantes. A aplicação dos questionários foi precedida pela apresentação do Termo de Consentimento Livre e Esclarecido. O questionário era composto por vinte questões, sendo dezenove fechadas e uma aberta.

A coleta de dados aconteceu na Clínica Escola de Odontologia da UESPI (CEO-UESPI), durante período de aula e após contato prévio com o professor da disciplina que estava sendo ministrada. O tempo de aplicação do questionário foi de aproximadamente 30 minutos.

Os dados foram tabulados e analisados por estatísticas descritivas.

\section{RESULTADOS E DISCUSSÃO}

Dos 92 estudantes, 66 aceitaram participar da pesquisa. Os resultados quanto aos dados sociodemográficos e referentes às famílias dos discentes constam da tabela 1 .

Nessa amostra há predominância de mulheres, jovens com idade média de 21 a 24 anos e solteiros(as), concordando com resultados de pesquisa realizada em 2011 em universidade do Sul do Brasil, na qual foi observado e discutido o predomínio de mulheres, o que denominaram de "processo de feminização" nos cursos de graduação em Odontologia ${ }^{2}$.

Os negros ainda são minoria no curso de Odontologia da UESPI, semelhante ao que foi identificado em pesquisa realizada na Universidade Federal de Pernambuco 5 .

Há um predomínio de estudantes naturais do estado do Piauí, seguidos do Ceará e Maranhão, e grande parte destes são dependentes financeiramente dos pais. Dados referentes à família dos estudantes indicam que pouco menos da metade dos pais ou responsáveis têm nível superior completo. No tocante à renda familiar, a faixa de 4 a 6 salários mínimos foi a mais relatada.

Os resultados da pesquisa demonstram também que o número de famílias com renda de 1 a 3 salários mínimos tem aumentado gradativamente, observando-se assim que não existe domínio da classe alta na universidade, como visto em outro estudo $^{6}$. Dados positivos para o aumento de estudantes da classe média são semelhantes aos encontrados em um estudo realizado em universidade de Pernambuco. ${ }^{7}$

A maior parte desses estudantes cursou ensino 
Tabela 1. Distribuição dos estudantes quanto aos dados sociodemográficos

\begin{tabular}{|c|c|c|c|}
\hline \multirow{3}{*}{$\begin{array}{l}\text { Variáveis } \\
\text { Gênero }\end{array}$} & & n & $\%$ \\
\hline & Feminino & 39 & $59 \%$ \\
\hline & Masculino & 27 & $41 \%$ \\
\hline \multirow[t]{3}{*}{ Idade } & 16 a 20 anos & 22 & $33 \%$ \\
\hline & 21 a 24 anos & 39 & $59 \%$ \\
\hline & Mais de 25 anos & 5 & $8 \%$ \\
\hline \multirow[t]{5}{*}{ Raça } & Branco & 28 & $42 \%$ \\
\hline & Pardo & 29 & $44 \%$ \\
\hline & Preto & 7 & $11 \%$ \\
\hline & Amarelo & 2 & $3 \%$ \\
\hline & Indígena & 0 & 0 \\
\hline \multirow[t]{12}{*}{ Estado de origem } & Piauí & 42 & $63,64 \%$ \\
\hline & Ceará & 6 & $9,09 \%$ \\
\hline & Maranhão & 5 & $7,58 \%$ \\
\hline & Distrito Federal & 2 & $3,04 \%$ \\
\hline & São Paulo & 2 & $3,04 \%$ \\
\hline & Espírito Santo & 1 & $1,51 \%$ \\
\hline & Pará & 1 & $1,51 \%$ \\
\hline & Paraíba & 1 & $1,51 \%$ \\
\hline & Pernambuco & 1 & $1,51 \%$ \\
\hline & Rio de Janeiro & 1 & $1,51 \%$ \\
\hline & Tocantins & 1 & $1,51 \%$ \\
\hline & Não informou & 3 & $4,55 \%$ \\
\hline \multirow[t]{2}{*}{ Estado civil } & Solteiro & 61 & $92 \%$ \\
\hline & Casado & 5 & $8 \%$ \\
\hline \multirow[t]{3}{*}{ Dependente dos pais } & Sim & 57 & $86 \%$ \\
\hline & Não & 8 & $12 \%$ \\
\hline & Não informou & 1 & $2 \%$ \\
\hline \multirow[t]{4}{*}{ Ensino fundamental } & Escola pública & 28 & 42 \\
\hline & Escola particular & 33 & 50 \\
\hline & Escola particular com bolsa parcial & 4 & 6 \\
\hline & Escola particular com bolsa Integral & 1 & 2 \\
\hline \multirow[t]{4}{*}{ Ensino médio } & Escola pública & 26 & 39 \\
\hline & Escola particular & 35 & 53 \\
\hline & Escola particular com bolsa parcial & 4 & 6 \\
\hline & Escola particular com bolsa Integral & 1 & 2 \\
\hline \multirow[t]{6}{*}{ Escolaridade dos pais } & Ensino fundamental incompleto & 8 & 12 \\
\hline & Ensino fundamental completo & 5 & 7,5 \\
\hline & Ensino médio incompleto & 2 & 3 \\
\hline & Ensino médio completo & 17 & 26 \\
\hline & Ensino superior incompleto & 5 & 7,5 \\
\hline & Ensino superior completo & 29 & 44 \\
\hline \multirow{4}{*}{ Renda familiar mensal } & 1 a 3 salários mínimos & 20 & 30 \\
\hline & 4 a 6 salários mínimos & 25 & 38 \\
\hline & Mais de 6 salários mínimos & 20 & 30 \\
\hline & Não informou & 1 & 2 \\
\hline
\end{tabular}


fundamental e médio em escola particular, semelhante ao encontrado em outras pesquisas com estudantes de Odontologia ${ }^{2,7}$.

Quanto ao motivo de escolha para cursar Odontologia, desejo pessoal foi a resposta escolhida por $32(48,50 \%)$ discentes, $18 \quad(27,27 \%)$ responderam que foi a $2^{\circ}$ opção de curso, concordando com um estudo feito na Faculdade de Odontologia de Bauru/ USP, no qual o motivo que levou maior parte dos alunos a escolherem o curso foi afinidade/vocação ${ }^{8}$.

Sobre a participação em programas relacionados à pesquisa científica na faculdade, uma quantidade considerável $(24,36,36 \%)$ dos estudantes respondeu que o fazem frequentemente, sendo que $6(9,10 \%)$ relataram que nunca se envolveram com projetos de pesquisa durante a formação. Com relação à participação em eventos científicos $42(63,64 \%)$ estudantes afirmaram que participam com frequência e $62(93,94 \%)$ dos alunos responderam que a pesquisa científica durante o período de formação é muito importante.

Em relação a monitorias que são oferecidas no curso, encontrou-se que 44 discentes $(66,6 \%)$ se interessam por esse tipo de programa. Poucos (17, $25,75 \%$ ) estudantes fazem estágios e desses, na sua maioria $(14,82,75 \%)$ não são remunerados.

Após o término da graduação, 60 (90,91\%) pretendem trabalhar no âmbito particular e público de forma concomitante, $3(4,55 \%)$ somente no setor privado e $2(3,03 \%)$ somente no serviço público, discordando de um estudo realizado na Faculdade de Odontologia da Universidade de São Paulo, onde a maioria $(58,07 \%)$ dos estudantes preferiram um emprego privado 9 . Concordando com a realidade da UESPI, estudo na Universidade Federal de Santa Maria e na Pontifica Universidade Católica do Rio Grande do Sul mostraram que apenas uma minora (3\% e $11 \%$, respectivamente) pretende exercer exclusivamente a clínica particular ${ }^{10}$.

No presente estudo, 27 (40,90\%) dos estudantes estimam como renda inicial mais de
$\mathrm{R} \$ 3.000,00$ - em desacordo com estudo realizado na região Sul, que evidenciou estimativa inicial de até $\mathrm{R} \$ 1.500,00^{10}$.

A grande maioria $(64,97 \%)$ dos alunos pretendem realizar especialização e as duas áreas de maiores interesses são Cirurgia $(16,24 \%)$ e Ortodontia (13, 20\%), e 14 (21\%) ainda não sabem qual área pretendem seguir, concordando em parte com estudos realizados no Sul do Brasil ${ }^{2,10}$ nos quais as áreas de maior interesse foram Ortodontia e Prótese.

No exercício da profissão, 45 (68,19\%) esperam se realizar pessoal e profissionalmente, 17 $(25,75 \%)$ pretendem fazer promoção de saúde e somente $4(6,06 \%)$ manifestaram desejo de realização financeira, concordando com estudos em que a promoção de saúde não teve domínio sobre as demais alternativas, mas também não foi deixada em último plano ${ }^{9-10}$.

Em pergunta aberta, os alunos deveriam dizer de forma concisa qual era sua expectativa quanto a sua futura profissão, sendo respondida por 60 $(90,9 \%)$ e deixadas em branco por $6(9,1 \%)$. Dentre as respostas mais citadas estão a realização pessoal e financeira, valorização e reconhecimento profissional, bem como promoção de saúde e contribuição para o bem-estar da população.

\section{CONCLUSÃO}

Os resultados do presente estudo demonstraram que o perfil do estudante de Odontologia da UESPI é caracterizado por jovens na faixa etária entre 21e 24 anos, solteiros e a maioria se autodeclara mulher. Grande parte dos estudantes são egressos de escolas particulares e filhos de pais com escolaridade de nível superior. São muito engajados com pesquisa e iniciação científica dentro e fora da universidade. Suas perspectivas quanto à profissão incluem realização pessoal, promoção de saúde e valorização da classe. 


\section{ABSTRACT}

Profile of Dentistry students from the Universidade Estadual do Piauí

The present study aimed to know the academic and sociodemographic profile of dentistry students from the Universidade Estadual do Piauí. The research was a cross-sectional study with quantitative approach. A questionnaire containing questions about the students' socioeconomic and academic aspects was applied. Among the 92 students enrolled, 71\% (66) participated in the study, of these 59\% (39) are women, $92 \%$ (61) single, 59\% (39) aged 2124 years, 38\% (25) from a favored economic class and 44\% (29) who called themselves white. Regarding the reason for choosing the course, personal desire was the answer chosen by $48.50 \%$ (32) of the students. Scientific research was classified as very important during training and after graduation, 97\% (64) intend to specialize, being 'Surgery' $(16,24 \%)$ and 'Orthodontics' $(13,20 \%)$ the areas of most interest. Prospects for the profession relate to personal/professional achievement and health promotion. Based on the results, we identified the profile of the Dentistry student at Piauí State University, their expectations and what they intend to accomplish after their graduation.

Descriptors: Dentistry. Job Market. Students.

\section{REFERÊNCIAS}

1. Junqueira JC, Colombo CED, Tavares PG, Rocha RF, Carvalho YR, Rodrigues JR. Quem é e o que pena o graduando de Odontologia. Rev Odontol UNESP. 2002;31(2):269-84.

2. Toassi RFC, Souza JM, Rosing CK, Baumgarten A. Perfil sociodemográfico e perspectivas em relação à profissão do estudante de Odontologia da Universidade Federal do Rio Grande do Sul, Brasil. Rev Fac Odontol. 2011;52(1/3):25-32.

3. Brasil. Indicadores das graduações em Saúde. Gráfico 2: cursos de graduação em odontologia segundo grandes regiões; 2012.
[Acesso em 10/04/16]. Disponível em: http://www.obsnetims.org.br/uploaded/4_7 2013 _0_Odontologia.pdf.

4. Costa AMDD, Costa JR, Costa MD, Costa RD, Botrel TEA. Contribuição do perfil do aluno de graduação em Odontologia para a redefinição dos recursos usados pelo professor no processo ensino-aprendizagem. Rev Fac Odontol Lins. 2002;14(1):30-4.

5. Dália RCS, Cardoso SO. Perfil sociodemográfico dos alunos e identificação de situações de ensino-aprendizagem que interferem na motivação do aluno para aprender durante o curso de Odontologia da Universidade Federal de Pernambuco; 2008. [Acesso em 10/04/16]. Disponível em: https://www.ufpe.br/conic/index.php?optio $\underline{\mathrm{n}=\mathrm{com} \_ \text {content } \& v i e w=\text { article } \& \mathrm{id}=339 \& \text { Ite }}$ $\underline{\operatorname{mid}=243}$

6. Brustolin J, Brustolin J, ToassiRFC. Perfil do acadêmico de odontologia da Universidade do Planalto Catarinense Lages - SC, Brasil. Rev ABENO. 2006; 6(1) :70-6.

7. Gurgel LGF, Guimarães RP, Beatrice LCS, Silva CHV. Perfil dos discentes ingressos do Centro de Ciências da Saúde de UFPE. Rev Bras Educ Méd. 2012;36(2):180-7.

8. Bastos JRM, Aquilante AG, Almeida BS, Lauris JRP, Byella VT. Análise do perfil profissional de cirurgiões dentistas graduados na Faculdade de Odontologia de Bauru-USP entre os anos de 1996 e 2000. J Appl Oral Sci. 2003;11(4):283-9.

9. Ponte TM. Perfil psicológico e interesses profissionais de estudantes de Odontologia. [Tese]. São Paulo: Faculdade de Odontologia da Universidade de São Paulo; 2012.

10. Unfer B, Rigodanzo L, Hahn D, Manfredini D, Rodrigues E, Carvalheiro $\mathrm{CH}$. Expectativas dos acadêmicos de 
Odontologia quanto a formação e futura profissão. Saúde. 2004;30(1/2):33-40.

11. Campos FGG, Santos RF, Santos FCP. A importância da pesquisa científica na formação profissional dos alunos do curso de educação física do UNILESTEMG. Rev Dig Educ Fís. 2009;4(2).

12. Oliveira DL, Souza ES, Batista FJN, Alvez JV, Yarid SD. Perfil do aluno de Odontologia da Universidade Estadual do Sudoeste da Bahia. Rev Saúde. 2013;9(3):169-78.

13. Leite DFBM, Trigueiro M, Martins IMCLB, Neto TJL, Santos MQ. Perfil socioeconômico de 253 graduandos de odontologia de uma instituição privada em João Pessoa-PB em 2011. J Health Sci Inst. 2012;30(2):117-9.
14. Brasil. Ministério da Educação, artigo 16 do decreto n5.773 de 09 de maio de 2006: Instruções para elaboração de plano de desenvolvimento institucional. 2006. [Acesso em 10/04/16]. Disponível em: http://www4.mec.gov.br/sapiens/pdi.htm.

15. Secco LG, Pereira MLT. Formadores em Odontologia: profissionalização docente e desafios político-estruturais. Ciênc Saúde Coletiva. 2004;9(1):113-20.

\section{Correspondência para:}

Beatriz da Silva Rocha

e-mail: bmroocha@gmail.com

Rua Samuel Santos, 7095 Bairro Frei Higino

64207-012 Parnaíba/PI 